\title{
Ability to control GSR amplitude
}

\author{
WILLIAM G. HUGHES and GLENN D. SHEAN \\ College of William and Mary, Williamsburg, Va. 23185
}

This investigation attempted to study the effects of Eysenck's personality factors and differential feedback conditions upon ability to inhibit GSR amplitude to a CS. High-neurotic introverts and low-neurotic extroverts were assigned, in equal numbers, to three experimental groups. Group 1 received immediate feedback and explicit instructions as to the experimental task, Group 2 received explicit instructions, and Group 3 received the same series of classical trials without feedback or instructions. Results indicated that only those Ss receiving feedback and explicit instructions significantly reduced GSR amplitude over trials. No effect was observed for personality factors.

Whatever the outcome of the current debate over evidence for direct instrumental ANS conditioning, current evidence indicates that awareness of reward contingency and immediate feedback as to performance enables most Ss to control the ANS (Brener \& Hothersall, 1967; Grings et al, 1962; Martin et al, 1968; Shean, $1968 \mathrm{a}, \mathrm{b}, 1970$ ). In an investigation related to the ability to control the GSR, Martin et al (1968) report that GSR activity was enhanced when shock avoidance was made contingent upon the presence of a response and reduced when shock avoidance was contingent upon the inhibition of a response. These authors further report that the inhibiting contingency was the most difficult for most Ss and that there were wide individual differences in ability to inhibit the GSR.

Several authors have attempted to relate personality factors to autonomic function. Eysenck (1967) has formulated two dimensions of personality: introversion-extroversion and neuroticism, which are thought to be related to autonomic activity. He considers neuroticism to be directly related to ANS activity and concludes that neurotic Ss respond more strongly to stimuli, show greater variability of response, and take longer to return to prestimulation base lines. Despite Eysenck's argument that neuroticism and introversion-extroversion are independent of one another, evidence indicates that these factors may influence ANS activity in a similar fashion. Fahrenberg \& Delius (1963), in a factor analytic study of personality and autonomic variables, report a clear-cut dysthymic factor with high loadings on neuroticism and introversion which had appreciable loadings on six measures of autonomic reactivity. Scott \& Wilkinson (1962) report a significant relationship between adaptation of the GSR and introversion with GSR activity of extroverts adapting over trials significantly more quickly than that of introverts, and Gray (1970) argues that introverts form conditioned fear reactions more strongly than do extroverts because introversion involves a heightened sensitivity to punishment and warnings of punishment.

The present investigation will attempt to study the relationship between personality dimensions (neuroticism, extroversionintroversion), feedback conditions, and ability to control the GSR.

\section{SUBJECTS}

The Ss were 42 introductory psychology student volunteers. There were 22 males and 20 females.

\section{APPARATUS}

The experimental room was approximately $10 \times 20 \mathrm{ft}$, without window, and maintained at a constant temperature of $70^{\circ} \mathrm{F}$. The room was divided by a white partition that removed the recording equipment from the Ss' view. A $3-W$ lamp was mounted at the top center of the partition facing $\mathrm{S}$. The lamp served as the CS and was always lighted $6 \mathrm{sec}$ preceding the UCS. Two feet below and to either side of the white lamp were two additional 3-W lamps, one green and one red. These served as feedback signals during the trials in which $S$ was attempting to inhibit his GSR. The experimental room was dimly lit at all times. The $S$ sat on a dental chair that was placed in the center of a $7 \times 7 \times 7 \mathrm{ft}$ aluminum screen cubicle. The cubicle electrically isolated $\mathrm{S}$ from the surrounding room.

The UCS was a pulsated dc shock delivered to the right calf by a Phipps-Bird inductorium that was supplied with a $6-\mathrm{V}$ primary source. The CS-UCS interval and UCS duration were controlled by two Hunter 111-B timers.

\section{PROCEDURE}

The Maudsley Personality Inventory was administered to 128 introductory psychology students. The mean E-I score for this sample was 24 and the mean $\mathbf{N}$ score was 27 . In the present study, Ss scoring below 24 on the E-I scale and above 30 on the $N$ scale were classified as high-neurotic introverts, while Ss scoring above 24 on the E-I scale and below 24 on the $N$ scale were classified as low-neurotic extroverts. Each $S$ was assigned to one of three groups by an assistant who was not familiar with the purpose of the experiment. The groups were: F-A (feedback-awareness), A-O (awareness-no feedback), C-O (control). Each group was composed of seven high-neurotic introverts and seven low-neurotic extroverts. Number of males and females in each group was as follows: F-A, 6 males, 8 females; A-O, 9 males, 5 females; C-O, 7 males, 7 females.

\section{Experimental Session}

Upon entering the experimental room, $\mathbf{S}$ was seated in a reclining chair, and electrodes and sensors were attached. The level of shock was adjusted for each $\mathrm{S}$ so that shock was perceived as aversive but not painful.

Five preliminary trials were administered in order to measure for possible preexperimental differences in GSR reactivity between groups. A trial began when $E$ energized the $C S$ for $6 \mathrm{sec}$, followed immediately by a .5-sec UCS. The mean intertrial interval was approximately $30 \mathrm{sec}$.

Upon completion of the five preliminary trials, the following instructions were read to Group F-A: "I am interested in how well you can voluntarily control your internal responses when the warning light (indicate) comes on. Whenever the white light comes on, I want you to keep your responses at as low a level as you can. One method of controlling internal responses is to think about something other than the warning light. Some people have reported that thinking of pleasant past experiences helps to control responses. This is only a suggestion; you try any thinking process that you wish. I will be monitoring your responses each time the warning light comes on. If you are successful in keeping your responses to the warning light below a level I have preset, then I will flash this green light between the time the warning light comes on and you receive the shock. If you respond over the preset level, then I will flash this red light. Your job is to get as many green lights as you can."

$A-U$ received the identical instructions with the feedback portion omitted. $\mathrm{C}-\mathrm{O}$ received no instructions, but were told that the first series of trials had been completed and that several more would follow.

Following presentation of the instructions, all Ss participated in 20 experimental trials. Lamp color designations were balanced for F-A such that seven $S$ s received the green lamp as positive feedback and seven Ss received the red lamp. For $A-O$, these lamps were flashed in a random order during the CS-UCS interval, for C-O, the lamps were never flashed. 


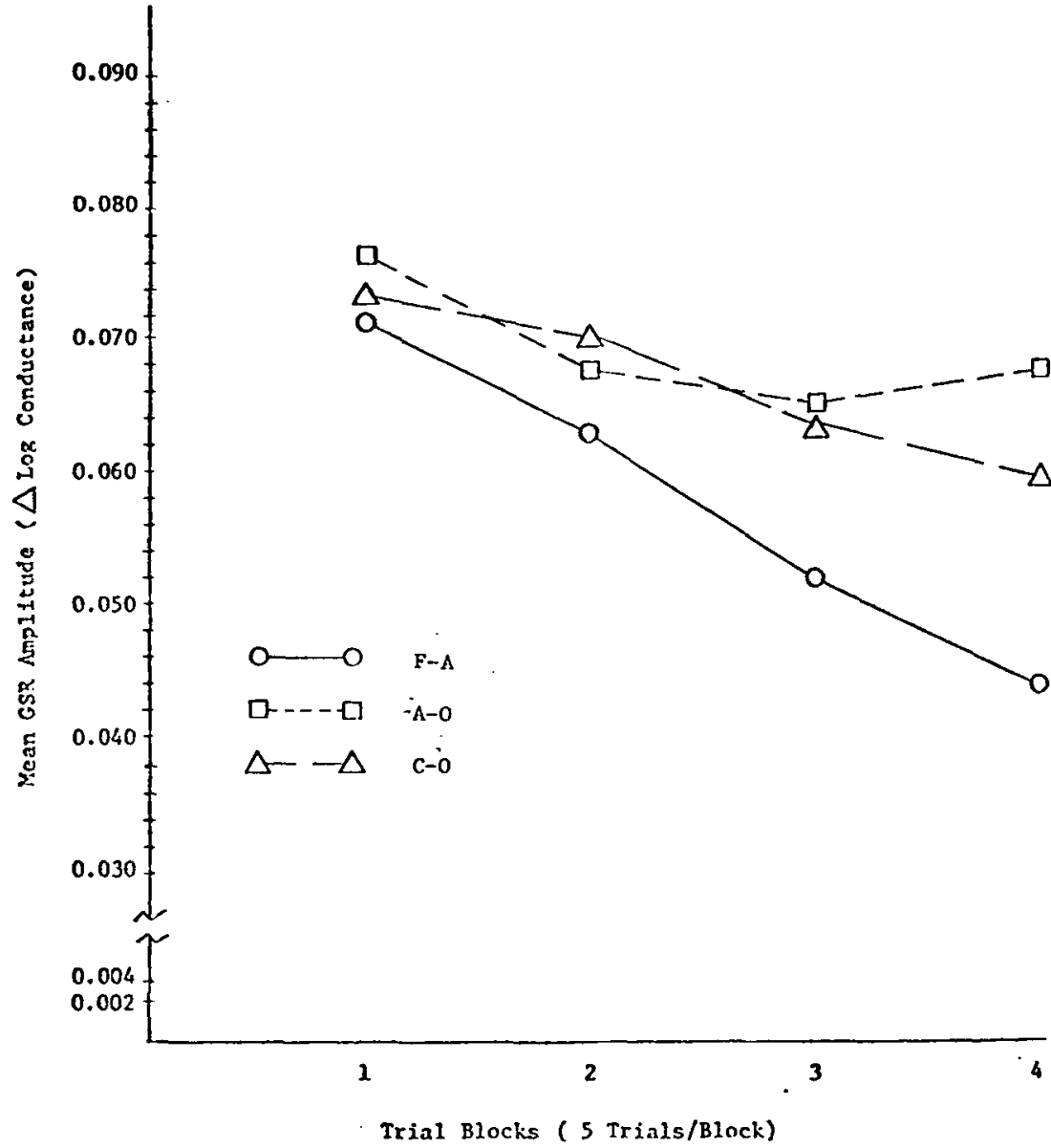

Fig. 1. Group responses as a function of experimental trials.

\section{RESULTS}

The GSR for each trial was defined as the change in skin conductance which occurred during the 6-sec interval between onset of the conditioned stimulus (CS) and administration of the unconditioned stimulus (UCS). All GSR data were analyzed as $\Delta$ log conductance.

Data for the preliminary trials were analyzed by a two-way analysis of variance (Bruning \& Kintz, 1968). Results of the analysis of variance indicated that there were no significant effects during preliminary trials (groups, $F=0.28, \mathrm{df}=2 / 36$; personality, $\quad F=0.64, \quad \mathrm{df}=1 / 36$; Groups by Personality, $F=0.30$, df $=2 / 36$ ).

Experimental trials were grouped into four blocks of five trials each. Experimental data were subjected to a test of homogeneity of variance and found to be acceptable for analysis of variance $\left(F_{\max }=5.87\right)$. Results of a three-way analysis of variance (Bruning \& Kintz, 1968) conducted on experimental trials indicated significant effects for trials $(F=26.43$, df $=3 / 108, p<.01$ ) and Groups by Trials $(F=2.94$, df $=6 / 108, p<.05)$.
These rssults indicate that (1) there was an overall tendency for GSR amplitude to decline as a function of trials, and (2) the GSR amplitude of Ss in the three experimental groups declined at different rates (Fig. 1).

The $F$ test for simple effects was used to determine the source of the Groups by Trials interaction. Results of this test indicated a significant difference between Group FA and Groups $A O \quad(F=4.37, \quad d f=2 / 108$, $p<.01)$ and $\mathrm{CO}(\mathrm{F}=3.97$, $\mathrm{df}=2 / 108, p<.01$ ). No significant difference was observed between Groups $A O$ and $C O \quad(F=.18$, df $=2 / 108)$.

\section{DISCUSSION}

Results of this experiment indicate that Ss receiving both immediate feedback and explicit instructions as to the response-feedback contingency were able to significantly reduce GSR amplitude over trials. Ss receiving explicit instructions as to the nature of the task but not performance feedback were not significantly different from control Ss.

These results appear to be inconsistent with a number of reports which indicate that information as to the CS-UCS sequence is sufficient for conditioning-like modification of a utonomic activity (Chatterjee \& Ericksen, 1962; Cook \& Harris, 1937 Fuhrer \& Baer, 1965; Grings \& Zeiner, 1965; Mowrer, 1938; Shean, $1968 \mathrm{a}, \mathrm{b})$. Several procedural differences may account for this apparent discrepancy. First, in the studies cited above, the procedure was that of a classical conditioning paradigm in which autonomic responses were elicited by a CS. This investigation utilized a classical paradigm to elicit GSR activity; however, experimental Ss were reinforced for controlling or inhibiting such activity during each trial. Thus, the task was that of controlling elicited activity for the nonspecific reinforcement of successfully performing an experimental task.

The design of this experiment would appear to indicate that feedback was the experimental condition which enabled Ss to inhibit GSR activity. However, since feedback (reinforcement) was combined with explicit instructions, one is in doubt as to whether the effect is due to feedback or to some necessary interaction of feedback and awareness. Several investigators have reported that direct feedback (reinforcement) of ANS activity using dim lights and money as reinforcers did not alter ongoing ANS activity (Mednick, 1964; Stern, 1967). The procedure utilized in this experiment differed from the above investigations in that feedback was contingent upon elicited GSR activity rather than upon changes in operant level. Nonetheless, the results of these investigations would indicate that feedback, in the form of dim lights, is in and of itself not an effective means of modifying ongoing GSR activity. Thus, it appears most likely that some interaction of feedback and awareness produced the significant effect presented in Fig. 3 .

Results indicated that high-neurotic introverts evidenced larger mean GSR amplitude than low-neurotic extroverts on all 25 preliminary and experimental trials; however, magnitude differences were not significant. Ss were selected on the basis of scores on these personality factors because previous research reviewed above indicated that both factors might be related to performance of the experimental task. Perhaps this assumption obscured any personality effect.

\section{REFERENCES}

BRENER, J., \& HOTHERSALL, D. Paced respiration and heart rate control. Psychophysiology, 1967, 4, 1-6.

BRUNING, J. W., \&INTZ, B. L. Computational handbook of statistics. Glenview: Scott, Foresman, 1968. 
CHATTERJEE, B. B., \& ERIKSEN, C. W. Cognitive factors in heart conditioning. Journal of Experimental Psychology, 1962, 64, 272-279.

COOK, S. W., HARRIS, R. E. Verbal conditioning of the galvanic skin response. Journal of Experimental Psychology, 1937, 21, 202-210.

EYSENCK, H. J. The biological basis of personality. Springfield, I11: Thomas, 1967.

FAHRENBERG, J., \& DELIUS, L. Eine Faktoren analyse psychischer und vegetativer Regulationsdaten. Nervenaryt. $1963,34,437-443$.

FUHREE, M. J., \& BAER, P. E. Differential classical conditioning: Verbalization of stimulus contingencies. Science, 1965. 150, 1479-1481.

GRINGS, W. W., CARLIN, S., \& APPLEY. $M$. Set, suggestion, and conditioning. Journal of Experimental Psychology. $1962,63,417-422$

GRINGS, W. W., \& ZEINER, A. Automatic response to words modified by sensitizing and conditioning experiences. Journal of
Psychosomatic Research, 1965, 8, 373-378.

MARTIN, R., DEAN, S., \& SHEAN, G. Selective attention and instrumental modification of the GSR. Psychophysiology, 1964, 4, 460-464.

MEDNICK, S. A. Learning. Englew ood Cliffs, N.J: Prentice-Hall, 1964.

MOWRER, O. H. Preparatory set: A determinant in motivation and learning Psychological Review, 1938, 45, 61-91.

SHEAN, G. D. The relationship between ability to verbalize stimulus contingencies and GSR conditioning. Journal of Psychosomatic Research, 1968a, 12. 245-249.

SHEAN, G. D. Vasomotor conditioning and awareness. Psychophysiology, 1968b, 5, 22-30.

SHEAN、G. D. Instrumental modification of the galvanic skin response: Conditioning or control? Journal of Psychosomatic Research, 1970, 14.

STERN, R. M. Operant conditioning of spontaneous GSR's: Negative results. Journal of Experimental Psychology, $1967,75,128-130$

\title{
Termination of a stressful task reduces fear of an approaching shock*
}

\author{
ALEXANDER HESS \\ Department of Behavioural Sciences \\ Tel-Aviv University Medical School, Tel-Aviv, Israel \\ and \\ SHLOMO BREZNITZ \\ Hebrew University, Jerusalem, Israel
}

An unavoidable electric shock was anticipated by $96 \mathrm{Ss}$ for $6 \mathrm{~min}$. Forty-eight of these were given another stressful task from Minute 4 to Minute $5 \frac{1 / 2}{2}$ of anticipation. It was found that, by terminating the stressful task 30 sec before the shock was due, Ss entered a relaxation phase and their heart rates revealed less fear of shock than that of the shock-only group.

There is some evidence that, when people anticipate an unavoidable frightening event, their fear reaction tends to follow a specific U-shaped pattern (Breznitz, 1967, 1968; Elliot, Bankart, \& Light, 1970). It is possible to analyze this pattern by dividing it into relevant psychological components. When the threat is first presented, there is a rise in measurable fear (Folkins, 1970); then follows a gradual relaxation, and finally, with the approach of the frightening event, the fear intensifies considerably. This particular pattern was found only with

* We are greatly indebted to Dr. Pinchas Yarden for his invaluable encouragement and to $S$. Biederman who helped at all stages of the research. situations in which the anticipation period was "empty" and the $S$ was passive.

We were interested in investigating the course of the fear reaction while the $S$, in addition to anticipating the frightening event, performs a stressful task. What would be the effect of this second stress upon the first one? What changes would take place in the temporal characteristics of the fear reaction? More specifically, what should one expect if the task is terminated before the execution of the initial threat? It is conceivable that the termination of one stress reduces tension, while, at the same time, the future frightening event is approaching, thus producing conflicting tendencies.
This study is a preliminary attempt to analyze some of the features of such a conflict.

SUBJECTS AND PROCEDURE

Ninety-six recruits, all high-level candidates for pilot training, were divided randomly into two groups. The shock-only group consisted of $\mathbf{4 8}$ Ss awaiting an unavoidable electric shock to be given exactly $6 \mathrm{~min}$ following a threat. The task + shock group consisted of 48 Ss who, in addition, had to take an achievement test while anticipating the shock. Ss were tested individually in a soundproof room. They were attached to a Galileo Polyanalyser Model PA 8a. The autonomic index that was measured was heart rate, using a Reflex Plethysmograph transducer attached to the thumb of the nondominant hand. The shock electrodes were attached to the back of the same hand. Shock was administered through a self-made electroshock with approximate intensity of $100 \mathrm{~V}$. Duration of shock was approximately $1 \mathrm{msec}$.

The Ss had earphones and a microphone. All communication was via an intercom system. Ss sat by a small table facing a clearly visible clock. Their dominant hands were free for use in the achievement task.

\section{INSTRUCTIONS}

In the shock-only group, Ss were attached to the instruments and given a $2 \cdot \mathrm{min}$ period of baseline recording. Following this period, they were told that they were taking a test of behavior under stress, that exactly 6 min following a starting signal they would be given a strong electric shock, and that their task was to observe the clock closely.

The task + shock group was pretested with the task before entering the physiological laboratory. The task consisted of visual screening of a page of random numbers, checking the occurrences of a particular number as quickly as possible. Following this task, they were attached to the polygraph and received the same instructions as the shock-only group. In the fourth minute of anticipation, they were given another visual screening task of the same type but using different numbers. The task was finished exactly $5 \frac{11}{2} \mathrm{~min}$ after the starting signal, i.e., $30 \mathrm{sec}$ before the shock was due.

Ss in the task + shock group received the task as relevant to the testing for pilot training, which turned it into a stressful task.

\section{RESULTS AND DISCUSSION}

The dependent variable in this study was heart rate. Every single heart beat was counted, and the relevant measures were transformed into scores 